\title{
Demonstrations of DC Microgrid and Virtual Power Plant Technologies on the Danish Island of Bornholm
}

Gabderakhmanova, Tatiana; Engelhardt, Jan; Zepter, Jan Martin Wilhelm; Sørensen, Thomas Meier; Boesgaard, Knud; Ipsen, Hans Henrik; Marinelli, Mattia

\section{Published in:}

Proceedings of the $55<$ sup $>$ th $</$ sup $>$ International Universities Power Engineering Conference 2020

Link to article, DOI:

10.1109/UPEC49904.2020.9209853

Publication date:

2020

Document Version

Peer reviewed version

Link back to DTU Orbit

Citation (APA):

Gabderakhmanova, T., Engelhardt, J., Zepter, J. M. W., Sørensen, T. M., Boesgaard, K., Ipsen, H. H., \& Marinelli, M. (2020). Demonstrations of DC Microgrid and Virtual Power Plant Technologies on the Danish Island of Bornholm. In Proceedings of the 55 International Universities Power Engineering Conference 2020 IEEE. https://doi.org/10.1109/UPEC49904.2020.9209853

\section{General rights}

Copyright and moral rights for the publications made accessible in the public portal are retained by the authors and/or other copyright owners and it is a condition of accessing publications that users recognise and abide by the legal requirements associated with these rights.

- Users may download and print one copy of any publication from the public portal for the purpose of private study or research.

- You may not further distribute the material or use it for any profit-making activity or commercial gain

- You may freely distribute the URL identifying the publication in the public portal 


\title{
Demonstrations of DC Microgrid and Virtual Power Plant Technologies on the Danish Island of Bornholm
}

\author{
Tatiana Gabderakhmanova*, Jan Engelhardt*, Jan Martin Zepter*, Thomas Meier Sørensen*, \\ Knud Boesgaard ${ }^{\S}$, Hans Henrik Ipsen $₫$, Mattia Marinelli*
}

\author{
${ }^{*}$ Department of Electrical Engineering \\ Technical University of Denmark (DTU) \\ Ris $\varnothing$ campus, Roskilde, Denmark
}

$\{$ tatigab, janen, jmwze, thms, matm\}@elektro.dtu.dk

\author{
$\S_{\text {Fremsyn ApS }}$ \\ Kgs. Lyngby, Denmark \\ knud@fremsyn.net
}

\author{
『Bornholms Energi and Forsyning \\ Rønne, Denmark \\ hhi@beof.dk
}

\begin{abstract}
The paper presents the scope and research activities, both analytical and experimental, to be carried out on the Danish Island of Bornholm under the 4-year (2019-2023) H2020 Insulae project. The two use cases taking place in Denmark are described. The first use case is dedicated to modelling and testing a low-voltage DC microgrid comprising a battery storage, renewable energy sources, and an EV fast charger, towards providing grid services. The second use case investigates the potential of a renewable-driven virtual power plant embracing different energy domains (electrical, heat, gas, transportation) for flexibility provision to the islanded energy system. Planned research activities for both use cases are described along with results in terms of design and engineering.
\end{abstract}

Index Terms - biogas plant, DC microgrid, distributed energy resources, electric vehicle, islanded energy system, modelling, renewables, storage system, virtual power plant

\section{INTRODUCTION}

The electric power sector, as well as transportation, heating and cooling sectors of the majority of the European (EU) islands are still fossil fuel-based, that in conjunction with the limitation of local energy resources makes them dependent on external supply. In case an electrical connection with the main land exists, most islands strongly depend on this link. The need for fuel transportation from the main land forms boundaries for electricity and heat costs. The global warming imposes additional restrictions on the use of fossil fuels, while the transportation sector remains the highest contributor to green gas emissions [1].

Nowadays, the large-scale implementation of renewable energy technologies and electrification of the transportation sector on EU islands are intensively promoted and supported

This work has received funding from the H2020 INSULAE project under the Grant Agreement No. 824433. For more information, visit http://insulaeh2020.eu/ by numerous national strategies and international agreements [2], [3]. These measures make it possible to reduce fuel dependency and environmental risks tied with fossil fuel exploitation while bringing significant benefits to climate change mitigation and increasing the economic viability of energy. At the same time, to keep energy systems with significant penetration of renewable energy sources (RES) and high-demanding electrical vehicles (EVs) balanced and stable, the incorporation of new technologies is required. Voltage and frequency control and black start capabilities are essential ancillary services, traditionally performed by fuel-based generation units, which in renewable-based power systems should be ensured for the grid by other technologies. In addition, enhanced energy management and control technologies, allowing to perform digital monitoring of bidirectional power flows, should be incorporated into the grid.

A number of research and demonstration projects of different scales focusing on the assessment of new technologies for providing flexibility and grid ancillary services have been carried out in EU. The effectiveness of EVs for providing grid balancing services was demonstrated in projects documented in [4], [5], and [6]. The Ecogrid and Ecogrid 2.0 projects have proved that grid balancing can be enhanced on the consumer side through flexible demand response, namely, reducible demand and excessive load [7], [8]. The efficiency of grid-scale battery energy storing systems (BESS) for providing grid-balancing services in islanded energy systems is being investigated in the BOSS project [9].

Alternatively, to keep the grid stable, the combination of distributed energy resources (DER) into self-sufficient energy systems - microgrids - of different scales with their own management and control which are able to provide grid services [10] could be effective. Specifically, the synergy between a mobile battery (an EV) and a stationary BESS can provide additional controllability features to the microgrid, while decreasing the impact of high power demand required 
during fast EV charging on the grid.

Electrical grid balancing can also be carried out through the synergy between electrical and other energy domains. However, the implementation and operation of multi-energy systems face challenges, particularly related with the necessity to perform centralized management and control of energy sources with different dynamics. Here, a virtual power plant (VPP) concept is potentially able to provide the necessary management and control functionalities. The concept was researched and experimentally tested in EU projects with focus on few specific technologies, whereas the role of a biogas power plant as part of a VPP for providing balancing services to the power system was not extensively investigated before.

In order to cover the research areas described above, two use cases are investigated by the Danish partners within the Insulae project [11]: a DC microgrid comprising a BESS, RES, and an EV fast-charger, and a multi-domain VPP, integrating a biogas plant, wind generation, PV generation, power and heat storages, and controllable and uncontrollable loads.

The remainder of the paper is divided as follows. Section II describes the energy system of the Bornholm island with specific focus on the energy-related issues and introduces two use cases to be investigated in relation to the island. Sections III and IV] present details of planned research, onsite development and demonstration activities, as well as early-stage design and engineering results for both use cases, respectively. Finally, Section $\mathrm{V}$ summarizes the paper.

\section{InSUlAe PRoJeCt AND THE BORNhOLM ISLAND}

The Insulae project [11] is an EU project, aiming at fostering the deployment of innovative solutions for the decarbonization of EU islands. As one of three demo sites for these interventions, the Danish Island of Bornholma (Fig. 19) was chosen due to the high technology reproduction potential.

Thanks to the specific location, social and economic peculiarities, as well as active energy position of Bornholm's municipality, the island is being continuously used as a fullscale laboratory for research and demonstration activities for a number of green energy-related projects [4], [6]- [9].

The power system of the Bornholm Island is represented by both conventional and renewable energy based generation. Table I lists the generation technologies installed on the island.

A ring-shaped $60 \mathrm{kV}$ distribution grid constitutes the backbone of the electrical grid. More than 28,000 consumers with a total peak load of $60 \mathrm{MW}$ are supplied via $1660 / 10 \mathrm{kV}$ substations, $9110 \mathrm{kV}$ feeders and around $100010 / 0.4 \mathrm{kV}$ substations [4], [12]. Worth noting is the high observability of the Bornholm's power grid on the $60 \mathrm{kV}$ and $10 \mathrm{kV}$ levels in terms of currents, voltages, and power.

Most of power generation sources on the island (central combined heat and power (CHP) plant in Rønne and all gridscale RES) are centrally controlled from a control room in

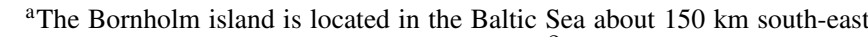
of Copenhagen. It has a total area of $588.3 \mathrm{~km}^{2}$ and is populated by more than 39,000 inhabitants.
TABLE I

Generation Units OF THE Bornholm ISLAND [4], [12]

\begin{tabular}{l|l|l|l}
\hline Type & $\begin{array}{l}\text { Number of } \\
\text { units }\end{array}$ & Fuel type & $\begin{array}{l}\text { Power } \\
\text { capacity } \\
{[\mathrm{MW}]}\end{array}$ \\
\hline $\begin{array}{l}\text { CHP plant (steam } \\
\text { turbine) }\end{array}$ & 1 & $\begin{array}{l}\text { Wood chips/ } \\
\text { coal/ oil }\end{array}$ & 36 \\
\hline $\begin{array}{l}\text { CHP biogas power } \\
\text { plant (2 gas engines) }\end{array}$ & 1 & Biomass & 3 \\
\hline Wind turbines & $\begin{array}{l}<0.1 \mathrm{MW}-24 ; \\
0.1 \ldots 1 \mathrm{MW}-1 ; \\
>1 \mathrm{MW}-17\end{array}$ & - & 37 \\
\hline $\begin{array}{l}<0.1 \mathrm{MW}- \\
\text { over 1000; } \\
>1 \mathrm{MW}-2\end{array}$ & - & 22 \\
\hline $\begin{array}{l}\text { Power generator } \\
\text { (steam turbine) }{ }^{\mathrm{b}}\end{array}$ & 1 & Oil & 25 \\
\hline Diesel generators & 14 & Diesel & 33 \\
\hline
\end{tabular}

${ }^{\mathrm{b}}$ run only under the islanded operation.

Rønne. The control is performed by BEOF, the local balance responsible party, owned by Bornholms municipality (BRK).

The power system is able to operate in grid-connected (normal) and islanded mode. In the normal operation mode, the island is electrically connected to Sweden through a subsea cable with a power transfer capacity of 60 MVA. This allows to balance the grid by importing or exporting power and thereby to withstand large highly variable power production from sun and wind. Under grid-connected operation, $100 \%$ of electricity produced on Bornholm comes from wind, PV or biomass. At the same time, local RES-based power generation it able to meet only around $60 \%$ of the annual power demand [13].

In case the sea cable is broken or under maintenance, the grid is operated in islanded mode. Hence, the biogas plant is supplying base load power, whereas the central CHP plant as well as oil- and diesel-based generation units act as main source for voltage and frequency balancing functionality. WT and PV production is stopped or curtailed significantly to avoid excessive power fluctuations in the grid.

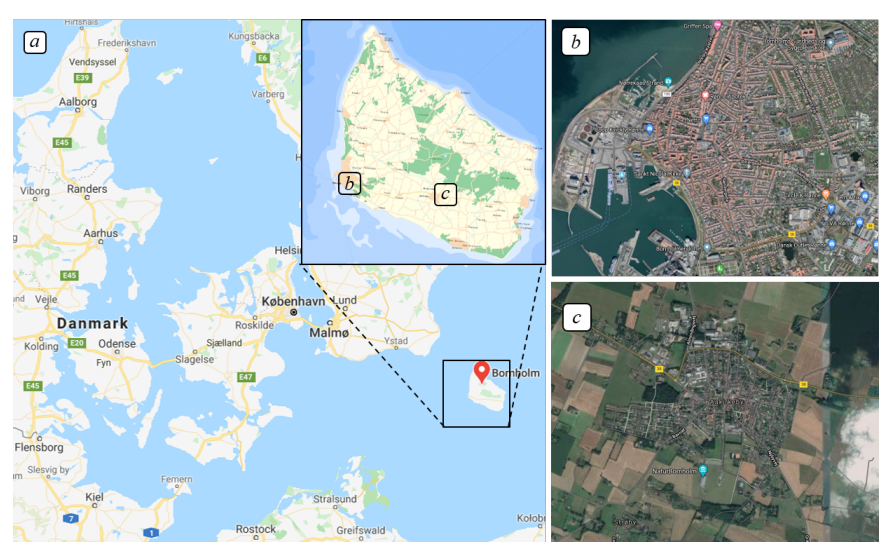

Fig. 1. Bornholm Island as a test site for the Insulae project: a) a map view of the island, $b$ ) Rønne city, the demo-site for the DC microgrid use case, $c$ ) Akirkeby district, the demo-site for the VPP use case. 
Since the fossil-fuel based grid balancing is an obstacle on the way to a full decarbonization of the island [14], the municipality is looking for new RES-and storage-based gridsupporting technologies.

In this context and given the characteristics of the energy system of the island, Bornholm is perfectly suited for testing, demonstration and customization for the broader replicability of the two technological solutions, which in combination with other technologies can provide grid services:

- the DC microgrid, combining RES, BESS and fast EV chargers. As a demonstration site, the city of Rønne, located in the south-west of the island (Fig. 1 p) is chosen, as it has the biggest potential of EV charging.

- the VPP, combining electrical, heating and transportation domains. The technology will be applied to the $60 / 10 \mathrm{kV}$ Åkirkeby substation, a grid node combining the largest RES-based generation facilities on the island (Fig. 17).

The results of demonstration activities, economical and technological, will feed the project's Investment Planning Tool-a simulation model, which will serve as a base for decision making regarding strategies and technologies for performing green transition for European islands.

The following two sections (Section III and Section IV) describe the current work progress, as well as plans for the future work and development for the two use cases, respectively.

\section{USE CASE 1: DC MICROGRID}

Taking into account the anticipated large-scale electrification of the transportation sector on the island [14], highpowered EV chargers could cause significant overloading in the distribution grid. This influence can be minimized by integrating EV chargers with BESS, possible leveraging on local RES, therefore limiting the power request from the grid.

The DC microgrid has 3 objectives: (i) providing grid services through the BESS, (ii) better integrating RES with less losses and lower investment costs, (iii) reducing EV fast charging impact on the distribution grid.

The work on the DC microgrid use case is divided into the following steps: (i) basic and detailed engineering, (ii) control architecture design, (iii) DC microgrid modelling and simulation towards grid services provision, (iv) feasibility studies, (v) commissioning of the DC microgrid on-site, (vi) hardware deployment and control strategies testing on-site.

\section{A. Basic and Detailed Engineering}

Fig. 2 presents the topology of the designed microgrid. It involves a PV system, a BESS, a wind turbine, and an EV fast charger (the installed capacities are in the order of $60 \mathrm{~kW}, 192$ $\mathrm{kWh}, 2 \mathrm{~kW}$, and $50 \mathrm{~kW}$, respectively). The microgrid has a 30 $\mathrm{kW}$ connection to the $0.4 \mathrm{kV}$ AC grid. The AC and DC sides are linked via a three-phase $0.4 \mathrm{kV} \mathrm{AC} / 0.62 \mathrm{kV}$ DC converter. Each power component is connected to a dedicated DC bus.

The key component of the microgrid is a 'Nerve Switch'an innovative reconfigurable power electronic-controlled battery [15]. In reconfigurable batteries, the cell topology can be rearranged in a real-time fashion according to the chosen cell characteristics (for example, state-of-charge (SOC)), generation unit and load characteristics, while keeping cells balanced across the battery or the battery string. Depending on the engagement of each individual cell, different levels of voltage, current and power can be obtained to ensure a proper current density [16]. Thus, each BESS string can be connected in parallel with any of the generation units or the $\mathrm{EV}$ in the microgrid, and DC/DC converters can be eliminated from the microgrid, reducing energy losses, investment costs, and failure risk [15].

The BESS is based on the lithium iron phosphate (LiFePO4) technology. It consists of three independent $64 \mathrm{kWh}$ strings with a nominal terminal voltage of $614 \mathrm{~V}(192$ cells $\times 3.2 \mathrm{~V}$ in series) connected to three dedicated buses.

The operation principles of the DC microgrid are to ensure that the power production from PV and WT is used primarily to charge EVs and, secondly, to inject into the AC grid with a controlled power level. Besides this, the storage will be also used to provide grid services such as frequency and voltage control.

The control system of the microgrid has a hierarchical architecture. The main control unit performing the energy management and ensuring the stable operation of the microgrid is the Energy Management System (EMS). The EMS communicates setpoints to Battery Management Systems (BMS) of each battery and the inverter. A string BMS transmits the command to each module BMS, that in turn controls electronic switches (MOSFETs) of each cell. The BESS control and cell switching logic is extensively described in [17].

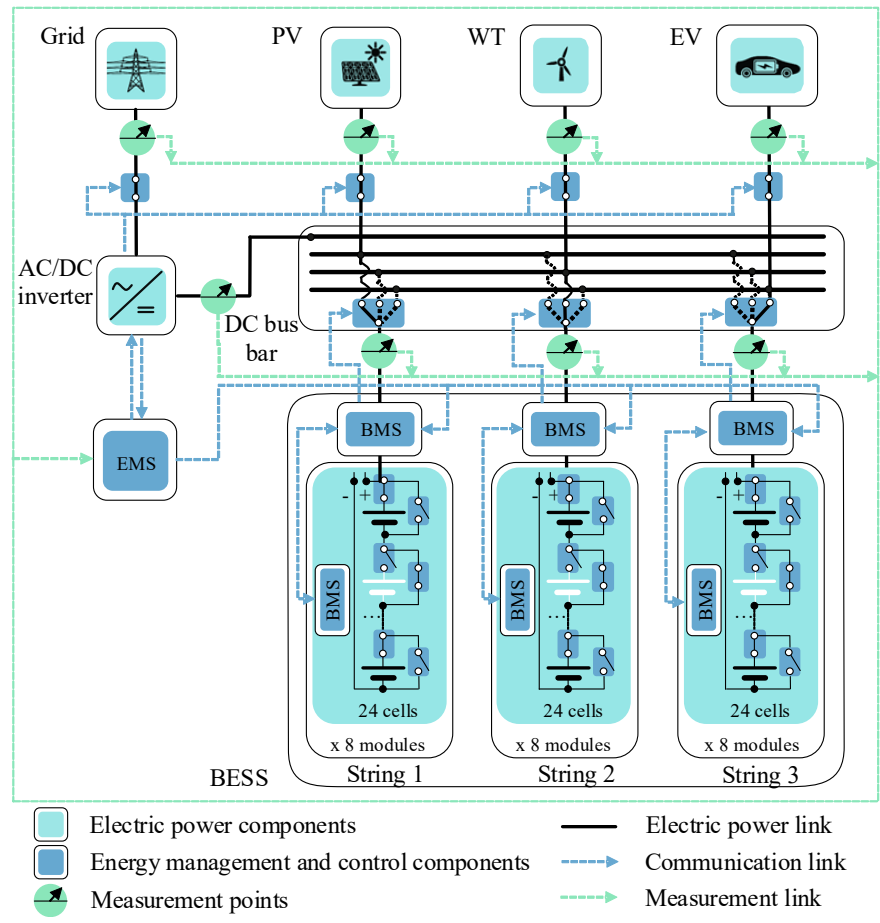

Fig. 2. DC microgrid block diagram. 
PV, WT, and EV charging control is performed by the BMS of the string they are connected to.

The proposed topology of the microgrid allows to decouple the main AC grid and the fast charger through the BESS, thus decreasing the impact of EV demands during fast charging.

Detailed engineering of the DC microgrid, including final sizing of the hardware, specification of the components, and other related steps, is subject of the next project stage.

\section{B. Modelling and Simulation}

The DC microgrid will be tested through modelling and simulation studies towards providing: (i) maximum power point tracking (MPPT) of PV and WT, (ii) power reference tracking at the grid connection point, (iii) fast EV charging, (iv) pure battery charging (unidirectional EV charging) and battery charging/discharging (bi-directional EV charging) to follow frequency or voltage droop control characteristics, (v) grid services (voltage and frequency control).

To perform dynamic studies of the designed DC microgrid and to test the control strategies, models of the microgrid are being developed both in MATLAB \& Simulink and DIgSilent PowerFactory.

For different research purposes, two types of battery model have been developed: a multi-cell model, fully reflecting the reconfigurable topology of the BESS, and a simplified battery model, representing the EV battery. In the multi-cell model, the battery dynamics are reproduced by a matrix of Thevenin equivalent circuits for each individual battery cell. It allows to incorporate an advanced cell switching algorithm, realized in the physical battery. In the simplified battery model the dynamic characteristics of the whole battery are represented by one Thevenin equivalent circuit, as this modelling approach is sufficient for the EV battery representation in this study.

A detailed description of the BESS and EV models, technical parameters of the batteries, as well as the results of an EV fast-charging scenario simulation are presented in [17].

\section{Further Work and Plans for the Development}

Besides models improvements and control strategies testing through simulations, the following further work is expected within the use case: (i) testing of a down-scaled copy of the BESS in the DTU Lyngby campus, (ii) commissioning of the DC microgrid on-site, (iii) hardware deployment and control strategies testing on-site. In parallel, feasibility analysis of the proposed technological solution will be performed.

The detailed engineering of the DC microgrid and the final version of the demonstration site layout will be completed by September 2020. The development of a full-size prototype of the DC microgrid on-site in Rønne will be started in September 2020, although some regulatory procedures and negotiations tied with the demo-site are already ongoing. The complete installation and commissioning of the system along with maintaining the grid connection will be finished by June 2021. After that, a series of experimental investigations, including testing novel control strategies, will be carried out on-site until the end of the Insulae project, June 2023.

\section{Use Case 2: Virtual Power Plant}

The objective of this use case is to demonstrate how different distributed energy resources - biogas, wind, solar, EVs, and heat storages - can be interlinked in order to further decarbonize the island of Bornholm. To this end, it is aimed at investigating possibilities for incorporating new biomass fractions for multi-energy services in the integrated island energy system.

Specifically, this use case addresses the question how a multi-domain VPP can achieve a secure electrical grid operation with high shares of renewable sources while exploiting synergies with other energy domains. In general, there is no clear-cut definition of a VPP, but it is commonly distinguished between commercial and technical VPPs, where the difference lies in the focus on either market or grid operations, respectively. The latter is of superior interest for the use case taking into account local grid constraints. Accordingly, the operation objectives of the VPP are to regulate system voltages and to ensure energy balances while maximizing the share of RES and handling their uncertainties. Furthermore, the VPP thereby tries to offset the usage of oil- and diesel-based generation units which are as of today used for grid balancing in the island's off-grid mode.

The following main research activities within this use case are foreseen: (i) VPP control system strategy development, (ii) flexibility potential assessment of the biogas plant for grid service provision, (iii) modelling and simulation studies, (iv) VPP feasibility assessment, (v) testing specific control strategies on-site.

\section{A. VPP architecture}

a) Physical Layout and Power Component Description: Figure 3 presents the single-line diagram of the prospective VPP setup, consisting of a CHP biogas plant, two wind farms, a large-scale PV installation, a grid-scale battery that is to be installed by January 2021 [9], two controllable loads (an electric heater and an aggregated EV fleet), as well as an inflexible community load. This VPP concept will be realized based on the 60/10 kV Åkirkeby substation.

b) Flexibility Potential of the Resources: The connected resources entail different flexibility potentials with respect to the services they provide. The possible sources of flexibility are: the biogas power plant with a gas storage buffer, three controllable wind turbines, the grid-connected battery system, and controllable loads, such as the electric boiler of the Østerlars district heating plant and the EV fleet.

\section{B. Control System Design}

a) Control Objectives, Performance Metrics and Constraints: As it was discussed earlier, the VPP control and operation should pursue the goal of keeping the power grid balanced while meeting not only electricity but also heat demands. At the same time, RES production should be kept at the maximum level. Thus, the control objectives are minimizing the overall cost on activating flexibility from RES and keeping optimal power quality. 


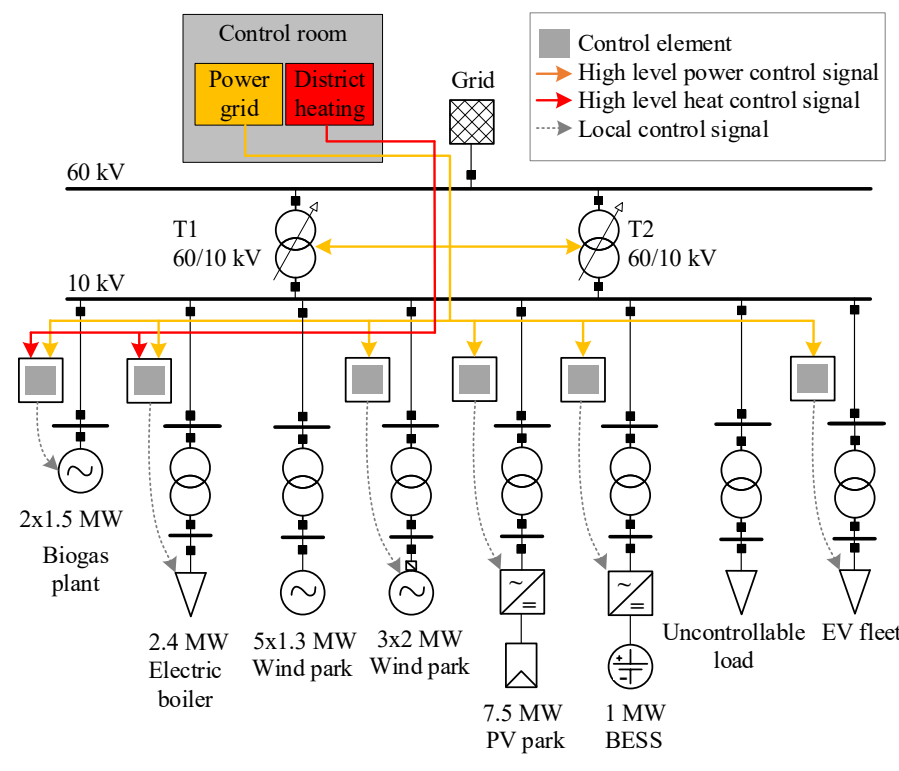

Fig. 3. Virtual power plant architecture.

The following constraints are taken into account during the control system design: (i) power quality requirements, (ii) local network constraints, (iii) power source flexibility constraints (for example, dependency of the WT power output on weather conditions), (iv) economical constraints.

b) Control Architecture: The VPP control architecture is presented in Figure 3. As it can be seen, it is based on a distributed vertical (hierarchical) topology [18]. The VPP is controlled from the central control room (CCR), that operates the whole island's power distribution grid, a part of the district heating networks, and most grid-scale power and heat generation facilities. The CCR is responsible for DER coordination based on collected data from all the VPP components, weather data, power quality requirements, optimisation constraints, and control objectives. Control signals are sent to the local controllers (LC), which in turn send signals to dedicated active units.

The proposed architecture allows to assign different control objectives to different control levels. Also, setpoints and other relevant data can be communicated between different local controllers. Thus, energy management, demand response, and advanced grid balancing control algorithms may be implemented based on this topology.

c) Control Algorithms: When operating on-grid, the energy management control algorithm could be used. Following the EMS control algorithm, the CCR performs active power flow coordination at the $10 \mathrm{kV}$ bus of the VPP: computation of power profiles of generation units and both controllable and uncontrollable loads and determining the optimal working point of the VPP. After it is done, power profiles are sent to the LCs of the controllable generation and consumption units. LCs in turn send final commands to the dedicated active units.

For the case of islanded operation of the Bornholm power system with a high share of RES, more advanced control strategies will be designed and tested to fulfil power quality control objectives. Considering the response speed, the BESS may be used as the main actor of the primary frequency control, whereas, for example, the aggregated EV fleet would provide the secondary frequency control.

To compensate variable wind and PV generation on the island without its significant curtailment, excessive power from WTs and PVs can be used to synthesize electrofuels and/or produce heat in the controllable electric boiler of the Østerlars district heating plant. Active power output of the controlled WT and the PV park can be regulated to provide grid balancing. Moreover, both facilities can provide reactive power control functionality when needed. To compensate gaps in WT and PV generation, the biogas plant can be used, since both heat and power outputs of the plant could be controlled by regulating not only the biomass infeed (the amount and also the composition of the biomass input), but also by flexible usage of the biogas storage, as well as by regulating the share of the biogas used directly for the electrofuel production. The efficiency of the biogas plant at providing grid support in offgrid operation mode is a subject of detailed modelling and simulation studies that are being carried out within the project (see IV-C for more details).

The above mentioned and other control strategies will be investigated through simulation studies (see IV-D). Optimal control strategies will be defined based on the simulation results, as well as feasibility assessment results.

\section{Flexibility Potential Assessment of the Biogas Plant}

The flexibility assessment is performed on the one hand by a thorough investigation of the biomass potential on the island, and on the other by modelling the specific dynamics and flexibility options of the biogas plant.

a) Biomass Potential Assessment: Bornholms Bioenergi biogas power plant plays an important role in the island's energy and waste treatment systems: by recycling manure and organic wastes, it produces green heat and power while reducing greenhouse gas emissions [19]. According to Bornholm's energy vision [14], the exploitation of new biomass resources could make the biogas plant a key player in the local bio-based economy, providing grid services and contributing to a secure and sustainable operation of the island's energy system.

The results of the study on local biomasses and waste resources on the island are presented in [19]. Realizing the estimated economically feasible potential would enlarge the yearly biogas production on the island by more than 4 times. This amount potentially covers a significant part of the electrical and thermal needs on the island, but also opens prospects for using the biogas for other purposes, such as transport fuels production. Thus, in the range of the project, it will be studied how the characteristics of the existing biogas CHP plant could be enhanced for incorporating and managing these new biomass resources, and what are the technical and economical possibilities for the partial conversion of the biogas into other fuel types. 
b) Biogas CHP Plant Modelling: A detailed technical description and characterization of the biogas production processes are given in [19]. Seen from an electrical engineering perspective, the presented model comprises the relevant dynamics of the 3-MW biogas plant, detailing the anaerobic digestion of raw infeed material, the gas storage and the combined heat and power production. The model has been validated against historical measurements of daily biogas and power production, as well as monthly thermal generation. A detailed mathematical description together with a thorough validation of the modelling results can be found in [19]. The biogas plant model is currently being implemented into a VPP setting for a further investigation on how the biogas plant can be utilized for flexibility provision. One direction of current modelling activities is to extend the biogas plant by an upgrading facility. It comprises on the one hand an electrolyzer used to convert surplus electricity to hydrogen, on the other a methanization module to upgrade biogas to biomethane by adding hydrogen. In this way, excess electricity from the VPP can be effectively stored as biofuel which may in turn be used for CHP generation or transportation.

\section{VPP Modelling and Simulation Studies}

A model of the VPP has been developed in DIgSilent PowerFactory. Currently, dynamic models of wind turbines and the EV load and dedicated control systems are being developed and integrated into the model. Afterwards, the developed dynamic model of the biogas plant will be incorporated into the VPP model. Meanwhile, consumption, power production, weather, and other data for the model verification and simulation studies are being gathered. Historical onesecond generation and consumption data for all the $10-\mathrm{kV}$ feeders of the substation will be used as the reference setpoints for the simulations. Through the modelling and simulation studies, flexibility provision potential of the VPP towards the voltage and frequency balancing under the normal operation and fault situations will be studied. The simulations will be run in the islanded and grid-connected operation modes. The modelling and simulation studies of the EV fleet role at flexibility provision to the local grid, considering the possibility of unidirectional and bidirectional energy transfer between the grid and the EV fleet, done based on the model developed is a subject of a dedicated investigation [20].

\section{E. Further Work}

As it was mentioned earlier, the analytical results will be supported by economic studies. Some of the scenarios and control strategies, whose effectiveness will be proven during the simulations, will be experimentally tested on-site on the Åkirkeby substation. Testing and demonstration activities are planned for a period from Spring 2021 to Spring 2023.

\section{CONCLUSIONS}

This paper presented the scope, objectives, as well as analytical and experimental activities, contributing to the acceleration and facilitation of the green transition of European islands, that are being carried out within the Insulae project on the Danish Island of Bornholm. The two examined use cases-the DC microgrid and the virtual power plant-are described. Initial project outputs, mainly consisting of design and engineering results, for both use cases are presented. Also, plans for the future research, as well as for demonstration activities on the Bornholm Island are introduced.

\section{REFERENCES}

[1] Greenhouse gas emissions from transport in Europe. [Online]. https://eea.europa.eu/data-and-maps/indicators/transport-emissions-ofgreenhouse-gases/

[2] Clean energy for all Europeans. [Online]. https://op.europa.eu/en/ publication-detail/-/publication/b4e46873-7528-11e9-9f0501aa75ed71a1

[3] The Renewables Grid Initiative. [Online]. https://renewables-grid.eu/

[4] A. Zecchino, A. M. Prostejovsky, C. Ziras and M. Marinelli, "Largescale provision of frequency control via V2G: the Bornholm power system case," Electr. Power Syst. Res. vol. 170, 2019, pp. 25-34.

[5] N. Banol Arias, S. Hashemi, P.B. Andersen, C. Træholt and R. Romero, "V2G enabled EVs providing frequency containment reserves: field results," Proceedings of 2018 IEEE Int. Conf. on Industr. Techn. (ICIT), pp.1814-19, 2018.

[6] K. Knezovic, S. Martinenas, P.B. Andersen, A. Zecchino, M. Marinelli, "Enhancing the role of electric vehicles in the power grid: field validation of multiple ancillary services." IEEE Trans. Transp. Electrification, vol. 3, pp. $201-209,2016$.

[7] EcoGrid EU - a prototype for European smart grids - Deliverable D6.7 Overall evaluation and conclusion, 2016.

[8] C. Ziras, C. Heinrich, M. Pertl and H.W. Bindner, "Experimental flexibility identification of aggregated residential thermal loads using behind-the-meter data." Appl. Energy, vol. 242, pp. 1407-1421, 2019.

[9] BOSS project: Bornholm Smart grid Secured - by grid connected battery systems. [Online]. https://boss-project.com/

[10] A. Majzoobi, A. Khodaei, "Application of microgrids in providing ancillary services to the utility grid." Energy, vol. 123, pp. 555-563, 2017.

[11] Insulae project: maximizing the impact of innovative energy approaches in the EU islands. [Online]. http://insulae-h2020.eu/

[12] A. González-Garrido, A. Thingvad, H. Gaztañaga, M. Marinelli, "Fullscale electric vehicles penetration in the Danish island of Bornholm optimal scheduling and battery degradation under driving constraints." J. Energy Storage, vol. 23, pp. 381-391, 2019.

[13] Bornholms Energi \& Forsyning - og samfundet omkring os. CSR RAPPORT 2018. [Online]. https://www.beof.dk/media/1740/beof-crsrapport-2018.pdf

[14] Bright Green Island Visionen - Bornholmermålene frem mod 2035 [Online]. http://brightgreenisland.dk/

[15] Nerve Switch technology, [Online]. https://nervesmartsystems.com

[16] S. Ci, N. Lin, D. Wu, "Reconfigurable battery techniques and systems: a survey," IEEE Access, vol. 242, pp. 1407-1421, 2019.

[17] J. Engelhardt, T. Gabderakhmanova, G. Rohde, M. Marinelli, "Reconfigurable stationary battery with adaptive cell switching for electric vehicle fast-charging." 2020 Proceedings of the 55th International Universities Power Engineering Conference (UPEC), pp. 1-6, Torino, 1-4 Sep. 2020.

[18] X. Han, K. Heussen, O. Gehrke, H. W. Bindner, B. Kroposki, “ Taxonomy for evaluation of distributed control strategies for distributed energy resources.” IEEE Trans. on Smart Grid, vol. 9, No. 5. pp. 51855195, 2017.

[19] J.M. Zepter, T. Gabderakhmanova, K.M. Andreasen, K. Boesgaard, M. Marinelli, "Biogas plant modelling for flexibility provision in the power System of Bornholm island." 2020 Proceedings of the 55th International Universities Power Engineering Conference (UPEC), pp. 1-6, Torino, 1 4 Sep. 2020.

[20] M. Ledro,"Design of a hybrid wind-electric vehicles power plant modelfleet model for ancillary services provision in Bornholm." MSc in Sustainable Energy, DTU, July 2020. 